\title{
The Relation of Parafibromin Expression with Clinicopathological Factors in Invasive Breast Carcinomas
}

\author{
Serap KARAARSLAN' ${ }^{1}$, Berhan GENÇ${ }^{2}$, Ahmet NART ${ }^{3}$, İsmail BÖREKÇiं ${ }^{3}$, Mehmet Hüsnü BUĞDAYCl $^{1}$
}

Department of 'Pathology, ${ }^{2}$ Radiology and ${ }^{3}$ General Surgery, Şifa University Faculty of Medicine, IZMIR, TURKEY

\begin{abstract}
Objective: We aimed to find the relationship between parafibromin expression and clinicopathologic variables of breast carcinoma.

Material and Method: Ninety-seven cases of invasive breast carcinoma diagnosed at our department between the years 2010-2013 were included in the study. The parafibromin expression state was compared with the estrogen receptor, progesterone receptor, cerbB2, Ki67 results, and the clinicopathological variables.

Results: Among 97 breast carcinoma cases, 66 (68\%) were invasive ductal carcinoma. The average age was 54.3 (min:25, max:100), and the average tumor size was $31.1 \mathrm{~mm}$ (min:7, max:120). Lymph node metastasis was detected in 58\% of the cases. Eleven were diagnosed with metastasis amongst 77 cases whose distant metastasis data could be reached. Eleven cases were lost due to breast carcinoma. As the tumor grade increased, the possibility of distant metastasis and lymph node metastasis increased as well ( $\mathrm{p}=0.04, \mathrm{p}=0.05$, respectively). The mean follow-up duration of the cases was $26.6 \pm 9.8$ (min. 6, max. 53) months, and there was no significant difference in survival between the other variables. Of the cases, $21.6 \%$ were negative, $9.3 \%$ were $(+)$ positive, $11.3 \%$ were $(++)$ positive and $57.7 \%$ were $(+++)$ positive for parafibromin. It was found that there was an inverse correlation between the Ki67 proliferation index and lymph node metastasis and the parafibromin expression ( $\mathrm{p}=0.018$, $\mathrm{p}=0.029$, respectively).
\end{abstract}

Conclusion: We suggest that parafibromin may be a possible prognostic and predictive parameter for breast carcinomas. As the data on this matter in the literature is limited, it would be beneficial to investigate the matter and evaluate its relationship with survival in larger series.

Key Words: Breast carcinoma, Immunohistochemistry, Lymph nodes, Metastasis, Parafibromin

\section{INTRODUCTION}

Breast cancer $(\mathrm{BC})$ is the most common diagnosed malignancy in females globally. It ranks second amongst cancer-related deaths after lung cancer. BCs have a wide range of morphological and molecular features (1). Therefore, the treatment is planned out according to the patient's clinical features and the tumor's pathological and molecular features. Age, tumor size, histological grade and lymph node status are the most significant identifiers that are used to predict the clinical course in the diagnosis period of BCs. Having a high proliferation index is accepted as a worse prognostic factor (2). The most important indicators that shape both pre and post-surgery treatment are the estrogen receptor (ER), the progesterone receptor (PR) and the human epidermal growth factor receptor (HER-2/cerbB2). According to these features, hormone therapy (tamoxifen and aromatase inhibitors), trastuzumab, the recombinant human anti-HER2 antidote (Herceptin ${ }^{\circ}$ Genentech, California,USA), and lapatinib, the dual HER1/HER2 tyrosine kinase inhibitor (Tykerb, GlaxoSmithKline, Philadelphia,USA), can be used (3-5).

(Turk Patoloji Derg 2016, 32:8-14)

Received : 25.06.2015 Accepted : 27.10.2015
Parafibromin is a new marker that has initially been used in the definitive diagnosis of parathyroid tumors. CDC73/ Hyperparathyroidism type 2 (HRPT2) is a suppressor gene (chromosome 1q25-q31) and codes parafibromin that contains 531 amino acids. Parafibromin is part of the polymerase-associated factor 1 (PAF1) / RNA polymerase II complex, which is critical for histone modification. Inactivity (germ-line mutations / somatic mutations) of the HRPT2 tumor suppressor gene is associated with the Hereditary Hyperparathyroidism-jaw syndrome (HHJTS) and sporadic parathyroid carcinoma. While the expression decreases and disappears in parathyroid carcinomas, the expression in sporadic parathyroid adenoma and hyperplasia is high (6-9). Due to the fact that it is a tumor suppressor gene, it could be predicted that the malignancy potential and aggressiveness increases as the parafibromin expression decreases. The first study on this subject in the literature was published by Selvarajan et al. in the year 2008 (10). No data in the English literature existed before that time.

Correspondence: Serap KARAARSLAN

Şifa Üniversitesi Tip Fakültesi, Patoloji Anabilim Dalı, İZMİR, TURKEY

E-mail: serapkaraarslan@gmail.com Phone: +90 2323434445 
In our study, both the features of parafibromin staining and its relation with the prognostic variables were investigated and the parafibromin staining features of the peritumoral normal breast parenchyma were evaluated.

\section{MATERIAL and METHOD}

The selection of the patients and tissue: Randomly chosen 97 BC's, diagnosed between the years 2010 - 2013 in the University Pathology laboratory, were included in the study. By selecting the blocks with tumor and normal breast parenchyma, it was aimed to evaluate the parafibromin expression of the peritumoral breast tissue as well as the carcinoma regions. Parafibromin, ER, PR, cerbB2 and Ki67 were immunohistochemically (IHC) applied to the slides of all selected blocks. The clinical features (recurrence, metastasis, death from disease) of the patients were acquired from the patient records. Pathological features (tumor grade, tumor subtype, lymph node status, perinodal invasion) were re-evaluated according to the standard protocols $(11,12)$.

Immunohistochemical staining: The 4 micron-thick sections were taken from the paraffin-embedded blocks of all the cases and put on the positively-charged slides and stained with parafibromin (sc-33638, dilution 1/100, Santa Cruz Bio-technology, USA), ER (IR084, ready to use, Dako, Denmark), PR (IR068, ready to use, Dako, Denmark), cerbB2 (A0485, dilution 1/400, Dako, Denmark) and Ki67 (IR626, ready to use, Dako, Denmark). After the deparaffinization of the sections, the antigen revelation was done by PT Link, Dako; staining was performed by the DAKO Autostainer Link 48. Normal parathyroid tissue was used as a positive control while the vascular structures in the breast stroma and the fibroblastic cells were used as a negative control for parafibromin. The cases that were evaluated by two pathologists (SK, MHB) as different in staining ratios, were re-evaluated together and the codecision used in statistical calculations.

The evaluation variables of the immunohistochemical staining: The cut-off data from previous research were used to evaluate the percentage and features of the parafibromin staining on the tumor cell nuclei, regardless of staining intensity. In this study, $0-5 \%, 5-25 \%, 26-50 \%$, $51-100 \%$ were accepted as negative, $(+),(++)$ and $(+++)$ positive respectively (13). The positive rate of ER and PR was evaluated as the percentage of staining in tumor cells. At least $1 \%$ rate in tumor tissue staining was considered as positive $(14,15)$. For the evaluation of the Ki67 proliferation index, the surface of the entire section was homogenized by scanning the stain and three areas were chosen to reflect the overall staining percentage. At least 400 cells were counted specifically for the percentage of staining in these areas with high magnification (x400). The $14 \%$ value that has been stated in the article by Cheang et al. was used as a cut-off value (16).

Statistical data analysis: The SPSS (Statistical Package for Social Sciences) Windows 18.0 (SPSS Inc., Chicago, USA) software program was used for statistical analyses. In addition to descriptive statistical methods, the Chi Square Test and Fisher's Exact Test were used in the comparison of categorical variables. Survival data was obtained with the Kaplan Meier, Log Rank and Cox Regression analyses. A p value $<0.05$ was accepted as statistically significant.

\section{RESULTS}

The clinical and pathological features of the cases are shown in Table I. Most of the invasive ductal carcinoma cases were grade 2 or 3 . As the tumor grade increased, the axillary lymph node metastasis (LNM) rate increased as well $(p=0.04)$. The relation between the increased tumor grade and distant metastasis was found to be statistically marginsignificant $(\mathrm{p}=0.05)$ (Table II). Eleven cases were diagnosed with distant metastasis among 77 cases whose metastasis data could be reached. The metastasis region was found to be the bone $(n=6)$, liver $(n=2)$, bone and liver $(n=1)$, thyroid $(\mathrm{n}=1)$ and distant lymph nodes $(\mathrm{n}=1)$ in order of frequency. The mean follow-up time of the cases was $26.6 \pm 9.8$ ( $\mathrm{min}$. 6 , max. 53) months. Eleven patients died due to BC related causes. Mean overall survival time was $48.23 \pm 1.5$ months. There was no significant difference in overall survival time according to age, tumor size, tumor type, tumor grade, LNM, perinodal invasion and distant metastasis.

The parafibromin expression was evaluated in the breast carcinoma field and the fields that included fibrocystic changes and ordinary breast parenchyma. Parafibromin was identified to be $(+++)$ positive in the ordinary breast parenchyma (Figure $1 \mathrm{~A}) .(++) /(+++)$ positivity was also present with the sclerosing adenosis and fibrocystic changes as well (Figure 1B,C). Parafibromin $(++)$ and $(+++)$ positivity was discovered in the areas where the high-grade ductal carcinoma $(n=8)$ was located (Figure 1D). The details about the parafibromin staining of the breast carcinomas are shown in the table and pictures (Figure 2A-E, Table I). The inverse correlation between the parafibromin expression and Ki67 proliferation index and LNM was remarkable ( $\mathrm{p}=0.018, \mathrm{p}=0.029$, respectively) (Table III). No statistically significant relationship between parafibromin expression and age, tumor size, tumor type, tumor grade, perinodal invasion, ER, PR, and CerbB2 
Table I: Clinicopathological features of the patients

\begin{tabular}{|c|c|c|}
\hline $\begin{array}{l}\text { Clinical and histopathological } \\
\text { features }\end{array}$ & $\begin{array}{c}\text { Number of } \\
\text { case }(\mathbf{n})\end{array}$ & $\begin{array}{c}\text { Percent } \\
(\%)\end{array}$ \\
\hline \multicolumn{3}{|l|}{ Age } \\
\hline$<40$ & 15 & 15.5 \\
\hline $40-49$ & 27 & 27.8 \\
\hline $50-64$ & 33 & 34 \\
\hline$\geq 65$ & 22 & 22.7 \\
\hline \multicolumn{3}{|l|}{ Histopathological type } \\
\hline Invasive ductal & 66 & 68 \\
\hline Invasive lobular & 1 & 1 \\
\hline Invasive ductal + lobular & 14 & 14.5 \\
\hline Others & 16 & 16.5 \\
\hline \multicolumn{3}{|l|}{ Tumor grade } \\
\hline 1 & 10 & 10.3 \\
\hline 2 & 64 & 66 \\
\hline 3 & 23 & 23.7 \\
\hline \multicolumn{3}{|l|}{ Diameter of tumors } \\
\hline$\leq 2 \mathrm{~cm}$ & 25 & 25.8 \\
\hline $2-5 \mathrm{~cm}$ & 61 & 62.9 \\
\hline$>5 \mathrm{~cm}$ & 11 & 11.3 \\
\hline \multicolumn{3}{|l|}{ Lymph node metastasis (axillary) } \\
\hline Absent & 41 & 42.3 \\
\hline 1-3 lymph nodes & 35 & 36.1 \\
\hline$\geq 4$ lymph nodes & 21 & 21.6 \\
\hline \multicolumn{3}{|l|}{ Perinodal invasion } \\
\hline Absent & 64 & 66 \\
\hline Present & 33 & 34 \\
\hline \multicolumn{3}{|l|}{ Distant metastasis } \\
\hline Present & 11 & 11.3 \\
\hline Absent & 66 & 68 \\
\hline Unknown & 20 & 20.7 \\
\hline \multicolumn{3}{|l|}{ Latest health status } \\
\hline Alive & 86 & 88.7 \\
\hline Dead & 11 & 11.3 \\
\hline \multicolumn{3}{|l|}{ ER } \\
\hline Negative & 21 & 21.6 \\
\hline Positive & 76 & 78.4 \\
\hline \multicolumn{3}{|l|}{ PR } \\
\hline Negative & 32 & 33.0 \\
\hline Positive & 65 & 67.0 \\
\hline \multicolumn{3}{|l|}{ cerbB2 } \\
\hline Negative & 67 & 69.1 \\
\hline Positive & 30 & 30.9 \\
\hline \multicolumn{3}{|l|}{ Ki-67 } \\
\hline$<\% 14$ & 53 & 54.6 \\
\hline$\geq \% 14$ & 44 & 45.4 \\
\hline \multicolumn{3}{|l|}{ Parafibromin } \\
\hline$\% 0-5$ & 21 & 21.6 \\
\hline$\% 6-25$ & 9 & 9.4 \\
\hline$\% 26-50$ & 11 & 11.3 \\
\hline$\geq \% 51$ & 56 & 57.7 \\
\hline
\end{tabular}

LNM: Lymph node metastasis, ER: Estrogen receptor, PR: Progesterone receptor.
Table II: The relationship between tumor grade and distant metastasis, lymph node metastasis

\begin{tabular}{|c|c|c|c|c|}
\hline \multirow{2}{*}{$\begin{array}{l}\text { Clinico- } \\
\text { pathological } \\
\text { features }\end{array}$} & \multicolumn{3}{|c|}{ Tumor grade } & \multirow{2}{*}{$p$ values } \\
\hline & 1 & 2 & 3 & \\
\hline \multicolumn{4}{|c|}{ Distant metastasis } & $p=0.04$ \\
\hline Present & 0 & $8(72.7)$ & $3(16.1)$ & \\
\hline Absent & $7(10.6)$ & $48(72.7)$ & $11(16.7)$ & \\
\hline Unknown & $3(15)$ & $8(40)$ & $9(45)$ & \\
\hline \multicolumn{4}{|l|}{ LNM } & $p=0.05$ \\
\hline Absent & $9(22)$ & $28(68.3)$ & $4(9.8)$ & \\
\hline $1-3$ & $1(2.9)$ & $22(62.9)$ & $12(34.3)$ & \\
\hline $3 \uparrow$ & 0 & $14(66.7)$ & $7(33.3)$ & \\
\hline
\end{tabular}

LNM: Lymph node metastasis.

was found. There was no significant difference in overall survival time according to the parafibromin expression, the Ki67 value ( $p=0.257, p=0.072$, respectively), ER, $P R$ and CerbB2.

\section{DISCUSSION}

Parafibromin was initially used in the differential diagnoses of the parathyroid tumors. Parafibromin was negative with HPT-JT related tumors and sporadic parathyroid carcinomas, but expression in hyperplasia and sporadic adenoma was encountered $(6,8)$.

Studies on parafibromin expression in other organ malignancies were then performed (13). The only article in the literature about the features of parafibromin staining in breast carcinomas is the study performed by Selvarajan et al. in 2008 (10). Parafibromin expression was evaluated with the micro array method in 163 breast carcinomas. Parafibromin staining features were compared with tumor size, tumor grade, lymphovascular invasion and cerbB2 expression. An inverse correlation between tumor size and parafibromin expression was observed $(\mathrm{p}=0.05)$. In addition, parafibromin was reported to be negative in the tumors with aggressive histopathological features (high grade, lymphovascular invasion and cerbB2 overexpression) (10). In our study, although no relationship was found between the parafibromin expression and tumor size, tumor grade, ER, PR and cerbB2 expression, a significant relationship between parafibromin expression and the Ki67 proliferation index and LNM was detected. In cases with increased parafibromin expression, the Ki67 proliferation index was lower and the number of LNM was less. These features suggested that there may be a relationship between low parafibromin expression and tumor aggressiveness. 

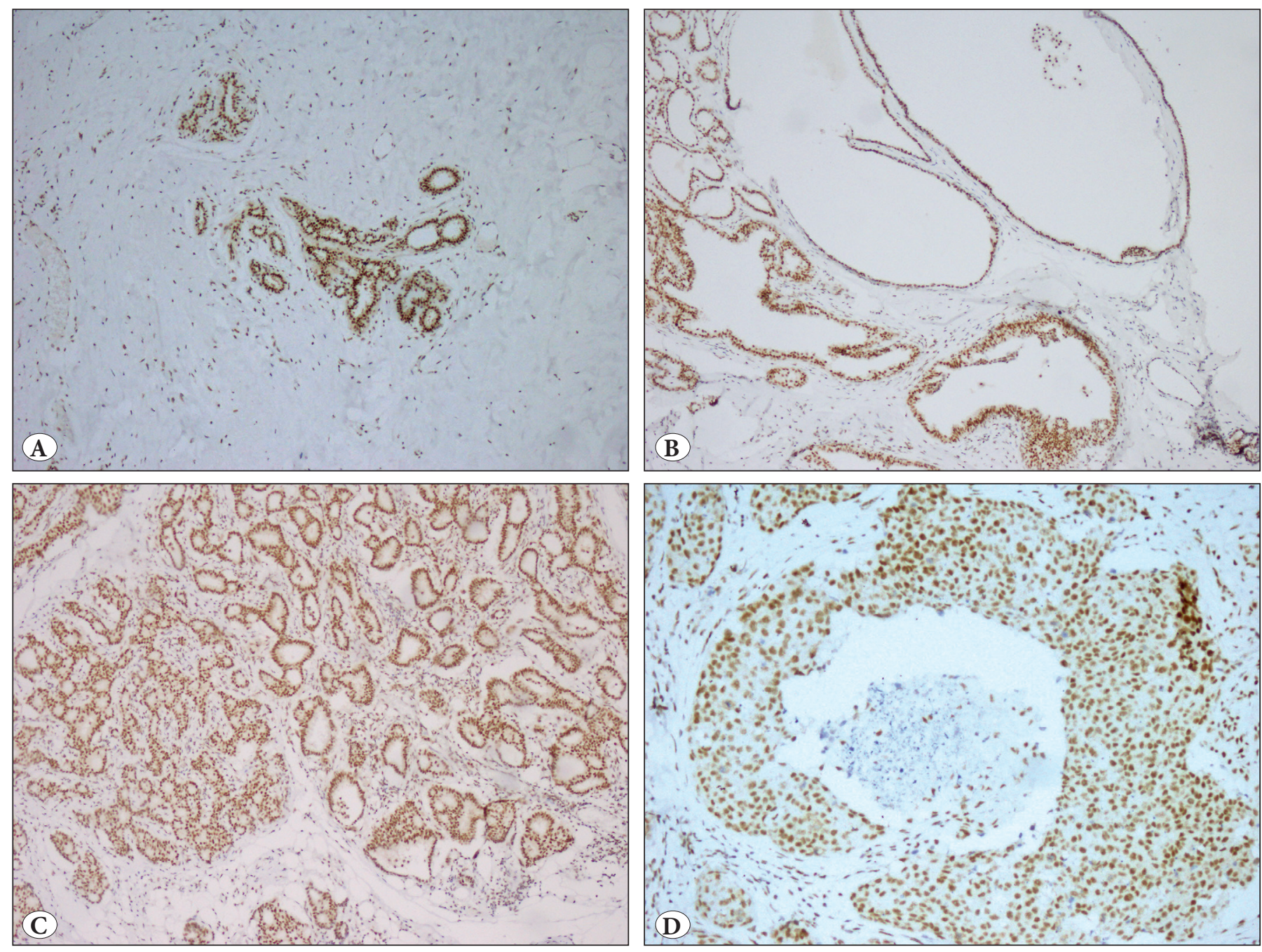

Figure 1: A) The strong positivity of the parafibromin in the ordinary breast parenchyma (parafibromin; $x 50)$. B, C) $(+++)$ parafibromin positivity in fibrocystic changes and sclerosing adenosis (parafibromin; x100). D) (+++) parafibromin positivity in the high-grade invasive ductal carcinoma (parafibromin; $\mathrm{x} 200$ ).

Table III: The relation between parafibromin expression and Ki67, lymph node metastasis

\begin{tabular}{|c|c|c|c|c|c|}
\hline \multirow[b]{2}{*}{ Immunohistochemical staining } & \multicolumn{3}{|c|}{ Parafibromin expression } & \multirow[b]{2}{*}{$\begin{array}{l}\geq 51 \% \\
\text { n (\%) }\end{array}$} & \multirow[b]{2}{*}{$p$ values } \\
\hline & $\begin{array}{l}0-5 \% \\
\text { n (\%) }\end{array}$ & $\begin{array}{c}\text { 6-25\% } \\
\text { n (\%) }\end{array}$ & $\begin{array}{c}26-50 \% \\
\text { n (\%) }\end{array}$ & & \\
\hline \multicolumn{5}{|l|}{ Ki67 } & $\mathrm{p}=\mathbf{0 . 0 1 8}$ \\
\hline$<14 \%$ & $11(52.4)$ & $7(77.8)$ & $10(90.9)$ & $25(44.6)$ & \\
\hline$\geq 14 \%$ & $10(46.6)$ & $2(22.2)$ & $1(9.1)$ & $31(55.4)$ & \\
\hline \multicolumn{5}{|l|}{ LNM } & $\mathrm{p}=\mathbf{0 . 0 2 9}$ \\
\hline Present & $8(19.5)$ & $0(0)$ & $3(7.3)$ & $30(73.2)$ & \\
\hline $1-3$ & $6(17.1)$ & $6(17.1)$ & $4(11.4)$ & $19(54.3)$ & \\
\hline $3 \uparrow$ & $7(33.3)$ & $3(14.3)$ & $4(19.0)$ & $7(33.3)$ & \\
\hline
\end{tabular}

LNM: Lymph node metastasis. 

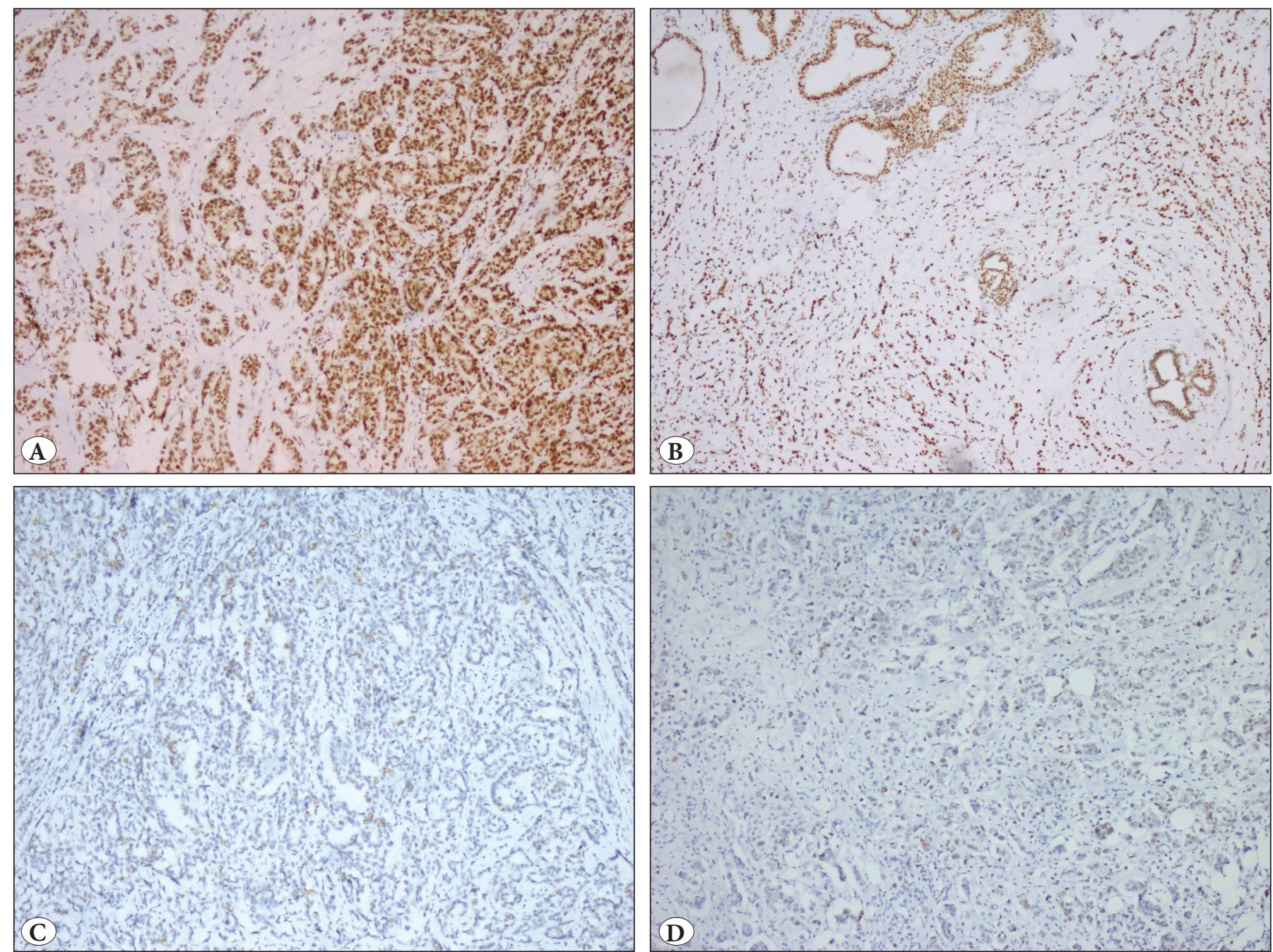

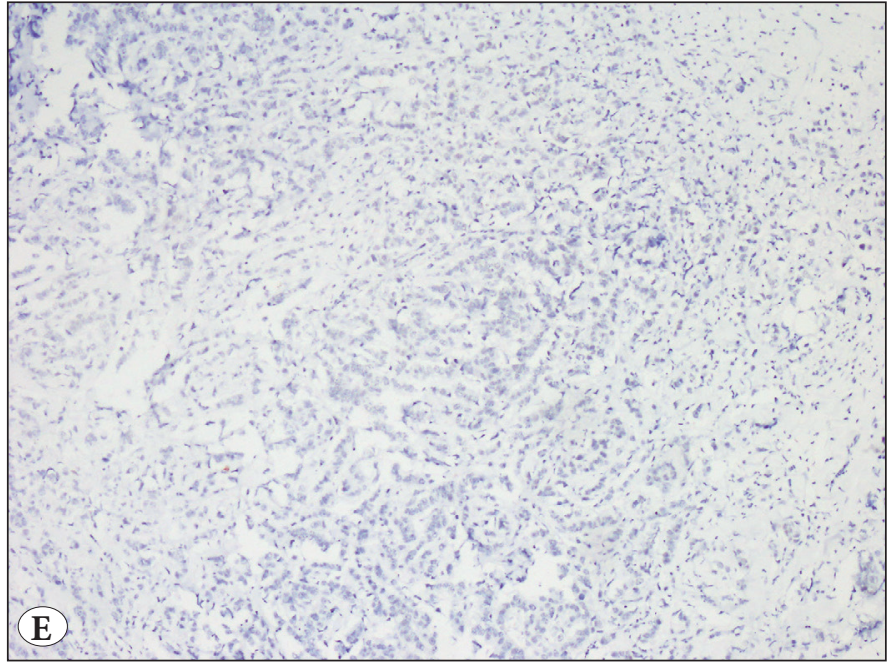

LNM is a parameter used to predict the clinical course in the breast carcinomas (17). In a study on stomach carcinoma by Zheng et al., it was reported that parafibromin expression decreases incrementally from the normal stomach mucosa
Figure 2: A) The (+++) positivity of the parafibromin in invasive ductal carcinoma morphology in tumor regions (parafibromin; $\mathrm{x} 100)$. B) The $(+++)$ positivity of the parafibromin in invasive lobular carcinoma regions and the $(+++)$ parafibromin positivity in the surrounding ordinary breast ducts (parafibromin; $\mathrm{x} 50$ ). C) The $(++)$ parafibromin positivity in breast carcinoma (parafibromin; $\mathrm{x} 100)$. D) The $(+)$ parafibromin positivity in invasive ductal carcinoma regions (parafibromin; x50). E) The parafibromin negativity in invasive ductal carcinoma regions (parafibromin; $\mathrm{x} 100)$.

to carcinoma. In our study, parafibromin was positive in normal breast parenchyma, fibrocystic regions and sclerosing adenosis but sufficient data to compare it with the carcinoma could not be retrieved. In the same study, 
a relationship between lymphatic invasion, invasion depth, LNM and tumor stage were detected. As a result, it was reported that it could predict an aggressive course in stomach carcinoma (13). Since a relationship between LNM and parafibromin expression loss was detected in our study, it could be suggested that loss of parafibromin expression could be related to tumor aggressiveness. Our study detected a significant relationship with decreasing parafibromin expression and LNM. In the cases that contained LNM $(\mathrm{n}=56), 33$ perinodal invasions had been seen, and in the cases that showed perinodal invasion, seven distant metastasis $(n=11)$ had been detected. In addition, eight of the 11 distant metastatic cases contained LNM. Even though there is no statistically significant difference between LNM and other parameters, the parallelism of the data may provide support for the aggressive behavior potential.

Ki67 proliferation index is a criterion used in the grading systems and it should be correlated with the other variables. It was reported that cases with high Ki67 proliferation index got worse than all the other groups, except for those who had not received treatment and the lymph nodenegative group (5). A statistically significant relationship was detected between parafibromin expression loss and increasing Ki67 proliferation index in our study. The Ki67 value was above $14 \%$ in the 8 cases among 11 cases who died. Thus, it was considered that parafibromin expression loss might predict a worse clinical course.

In conclusion, we encountered relationships with different variables compared to the first study on parafibromin expression in breast cancer. In some cases it is possible to make a prediction even with the morphological criteria, but various markers can be used other than the standard markers in some BC where a decision cannot be made. In our review, although no relationship was found between parafibromin expression and the tumor size, tumor grade, ER, PR and cerbB2 expression, a significant inverse relationship between the Ki67 proliferation index and LNM was detected. In the cases with increased parafibromin expression, the Ki67 proliferation index was lower and the number of LNM was less. These features suggest that there may be a relationship between decreased parafibromin expression and tumor aggressiveness, and supports further evaluation with larger samples.

\section{REFERENCES}

1. Sorlie T, Perou CM, Tibshirani R, Aas T, Geisler S, Johnsen H, Hastie T, Eisen MB, van de Rijn M, Jeffrey SS, Thorsen T, Quist H, Matese JC, Brown PO, Botstein D, Lønning PE, Børresen-Dale AL. Gene expression patterns of breast carcinomas distinguish tumor subclasses with clinical implications. Proc Natl Acad Sci U S A. 2001;98:10869-74.

2. Trihia H, Murray S, Price K, Gelber RD, Golouh R, Goldhirsch A, Coates AS, Collins J, Castiglione-Gertsch M, Gusterson BA; International Breast Cancer Study Group. Ki-67 expression in breast carcinoma: Its association with grading systems, clinical parameters, and other prognostic factors - a surrogate marker? Cancer. 2003; 97:1321-31.

3. Slamon DJ, Leyland-Jones B, Shak S, Fuchs H, Paton V, Bajamonde A, Fleming T, Eiermann W, Wolter J, Pegram M, Baselga J, Norton L. Use of chemotherapy plus a monoclonal antibody against HER2 for metastatic breast cancer that overexpresses HER2. N Engl J Med. 2001;344:783-92.

4. Tamoxifen for early breast cancer: An overview of the randomised trials. Early Breast Cancer Trialists' Collaborative Group. Lancet.1998;351:1451-67.

5. Howell A, Cuzick J, Baum M, Buzdar A, Dowsett M, Forbes JF, Hoctin-Boes G, Houghton J, Locker GY, Tobias JS; ATAC Trialists' Group. Results of the ATAC (Arimidex, Tamoxifen, Alone or in Combination) trial after completion of 5 years adjuvant treatment for breast cancer. Lancet. 2005;365:60-2.

6. Tan $\mathrm{MH}$, Morrison C, Wang P, Yang X, Haven CJ, Zhang C, Zhao P, Tretiakova MS, Korpi-Hyovalti E, Burgess JR, Soo KC, Cheah WK, Cao B, Resau J, Morreau H, Teh BT. Loss of parafibromin immunoreactivity is a distinguishing feature of parathyroid carcinoma. Clin Cancer Res. 2004;10:6629-37.

7. Shattuck TM, Välimäki S, Obara T, Gaz RD, Clark OH, Shoback D, Wierman ME, Tojo K, Robbins CM, Carpten JD, Farnebo LO, Larsson C, Arnold A. Somatic and germ-line mutations of the HRPT2 gene in sporadic parathyroid carcinoma. N Engl J Med. 2003;349:1722-9.

8. Gill AJ, Clarkson A, Gimm O, Keil J, Dralle H, Howell VM, Marsh DJ. Loss of nuclear expression of parafibromin distinguishes parathyroid carcinomas and hyperparathyroidismjaw tumor (HPT-JT) syndrome-related adenomas from sporadic parathyroid adenomas and hyperplasias. Am J Surg Pathol. 2006;30:1140-9.

9. Duan K, Mete Ö. Parathyroid carcinoma: Diagnosis and clinical implications. Turk Patoloji Derg. 2015;31:80-97.

10. Selvarajan S, Sii LH, Lee A, Yip G, Bay BH, Tan MH, Teh BT, Tan $\mathrm{PH}$. Parafibromin expression in breast cancer: A novel marker for prognostication? J Clin Pathol. 2008;61:64-7.

11. Sloane JP, Anderson TJ, Blamey RW, Brown C L, Chamberlain $\mathrm{J}$, Coyne J, et al. Pathology reporting in breast cancer screening. 2nd ed. National Coordinating Group for Breast Screening Pathology. Sheffield: NHSBSP Publications; 1995. 19-21. (NHSBSP Publication no:3.)

12. Elston CW, Ellis IO. Pathological prognostic factors in breast cancer. I. The value of histological grade in breast cancer experience from a large study with long-term follow-up. Histopathology. 1991;19:403-10. 
13. Zheng HC, Takahashi H, Li XH, Hara T, Masuda S, Guan YF, Takano Y. Downregulated parafibromin expression is a promising marker for pathogenesis, invasion, metastasis and prognosis of gastric carcinomas. Virchows Arch. 2008;452:14755 .

14. Thike AA, Chng MJ, Fook-Chong S, Tan PH. Immunohistochemical expression of hormone receptors in invasive breast carcinoma: Correlation of results of $\mathrm{H}$-score with pathological parameters. Pathology. 2001;33:21-5.

15. Hammond ME, Hayes DF, Wolff AC, Mangu PB, Temin S. American Society of Clinical Oncology/college of American Pathologists guideline recommendations for immunohistochemical testing of estrogen and progesterone receptors in breast cancer. J Oncol Pract. 2010;6:195-7.
16. Cheang MC, Voduc D, Bajdik C, Leung S, McKinney S, Chia SK, Perou CM, Nielsen TO. Basal-like breast cancer defined by five biomarkers has superior prognostic value than triple-negative phenotype. Clin Cancer Res. 2008;14:1368-76.

17. Fitzgibbons PL, Page DL, Weaver D, Thor AD, Allred DC, Clark GM, Ruby SG, O’Malley F, Simpson JF, Connolly JL, Hayes DF, Edge SB, Lichter A, Schnitt SJ. Prognostic factors in breast cancer. College of American Pathologists Consensus Statement 1999. Arch Pathol Lab Med. 2000;124:966-78. 